from young leafy shoots of the tree, Guazuma tomentosa Kth. So far as can be ascertained from collections of the adults only, it would thus appear that this is a highly polyphagous species.

I found it at Soledad only during February and March, but Dr. Salt took it there on 20th June, and at San Nicolas (Habana) on 15th April.

\title{
BIOLOGICAL NOTES ON NEMERITIS CANESCENS (GRAV.) (ICHNEUMONIDÆ).
}

By P. W. Whiting,

University of Pittsburg.

On September 7, 1926 at Lowell, Massachusetts, in a grain and feed store heavily infested with Ephestia kuehniella Zeller and Plodia interpunctella $\mathrm{Hb}$. there were observed a large number of females of Nemeritis canescens (Grav.) No males were to be found.

Six of these wasps were set with Ephestia larvæ and descendants were reared during the winter through six generations. Females only were produced totalling 3953 . Since all of these except the 415 of the first generation were reared from bred virgins and since no males could be found among the numerous specimens in the store, the species appears to be almost or quite thelytokous.

Dissection showed that many eggs may be laid within the tissues of one caterpillar although only one maggot develops. The caterpillar is not paralyzed but feeds and grows normally and usually spins a cocoon. Ordinarily the full-grown maggot ruptures the skin of the caterpillar and spins its own brownish cocoon within the white silken tube of the latter. Not infrequently, however, the caterpillar is able to form a chrysalis in which case its chitinous covering left intact encloses the cocoon and pupa of the wasp. Adult wasps may be kept alive for several days if fed on honey and water.

There have been bred from single females from five to 43 offspring, but it is very likely that this number might be con- 
siderably increased. Whenever a large number of caterpillars are supplied to one wasp, however, numerous moths appear so that many caterpillars escape being parasitized

No data were collected on the duration of the different stages of development, but under variable conditions of roomtemperature records were taken of times of setting parents and of collecting progeny. Maximum periods for a complete generation thus ranged from 27 to 48 days inclusive with frequencies given in two-day intervals as follows:-44, 59, 126, 151, 143, 100, $88,48,20,20,15$. These numbers show that the generation extends on the average slightly over a month, but may be somewhat shorter, while laggards may extend the time considerably.

\section{THE JURASSIC INSECTS OF TURKESTAN}

By T. D. A. Cockerell, University of Colorado.

In 1920 a very remarkable deposit of fossil insects of Jurassic age was discovered in the vicinity of Galkino, in Turkestan. The locality is within the territory of the so-called Cossack Republic, and is reached by the railway running east from Arys. Many of these insects have already been described by Martynov in Bull. Acad. Sci., Russia, ('25), but when I recently visited the Museum of the Academy at Leningrad, I was shown an amazing series of specimens, which when made known will profoundly influence many of our ideas concerning the age and evolution of various insect groups. The publications of Martynov on the Jurassic and Permian fossil insects will certainly be among the most important contributions to entomology in the next decade.

My wife and I had meant to visit the Galkino locality, but when we tried to make the necessary arrangements at Tashkent, so many difficulties presented themselves that it was impracticable to do anything. However, I was kindly permitted to study and describe some of the Galkino specimens in the Middle Asian Museum at Tashkent. Mr. Yankowsky, the director of 

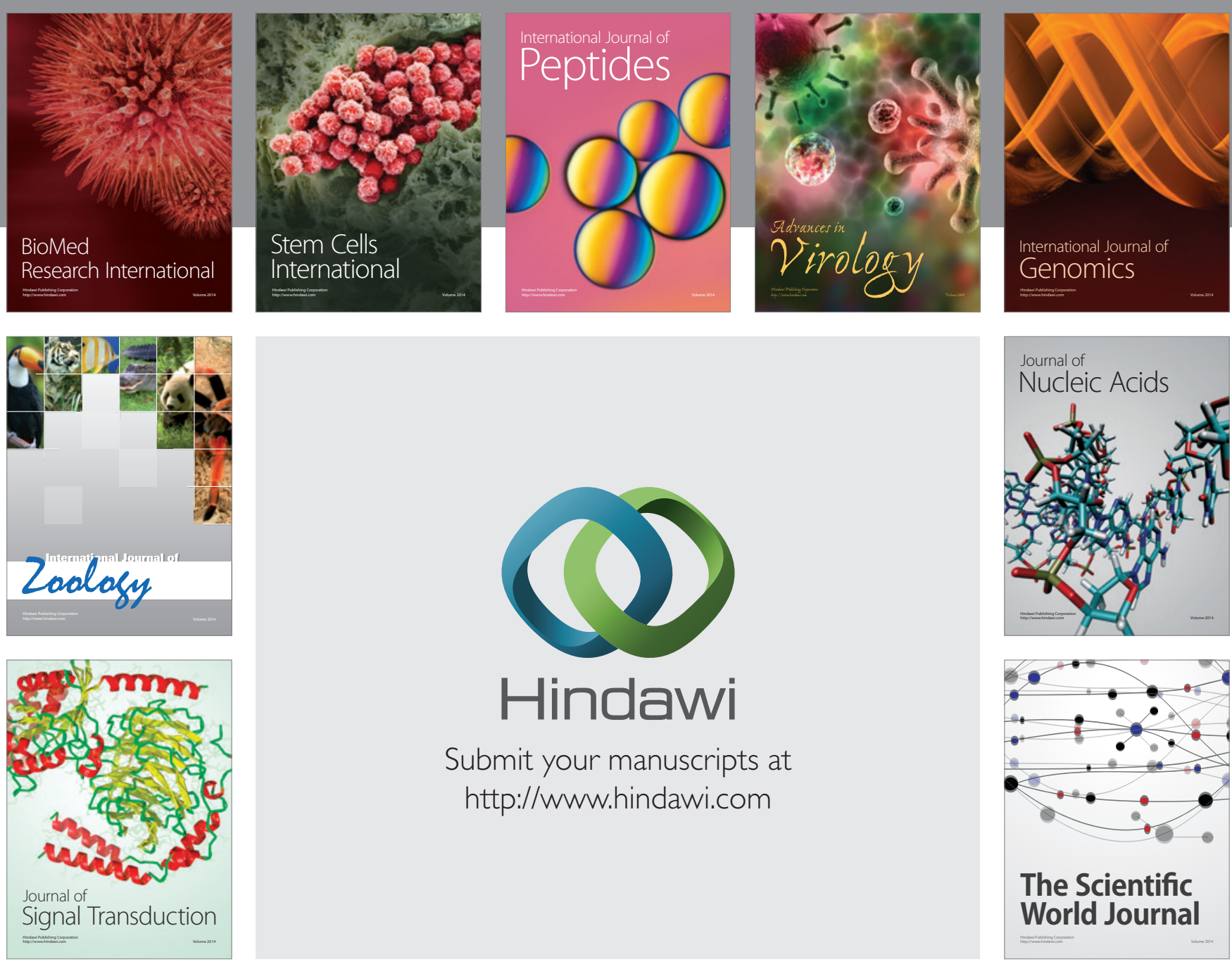

Submit your manuscripts at

http://www.hindawi.com
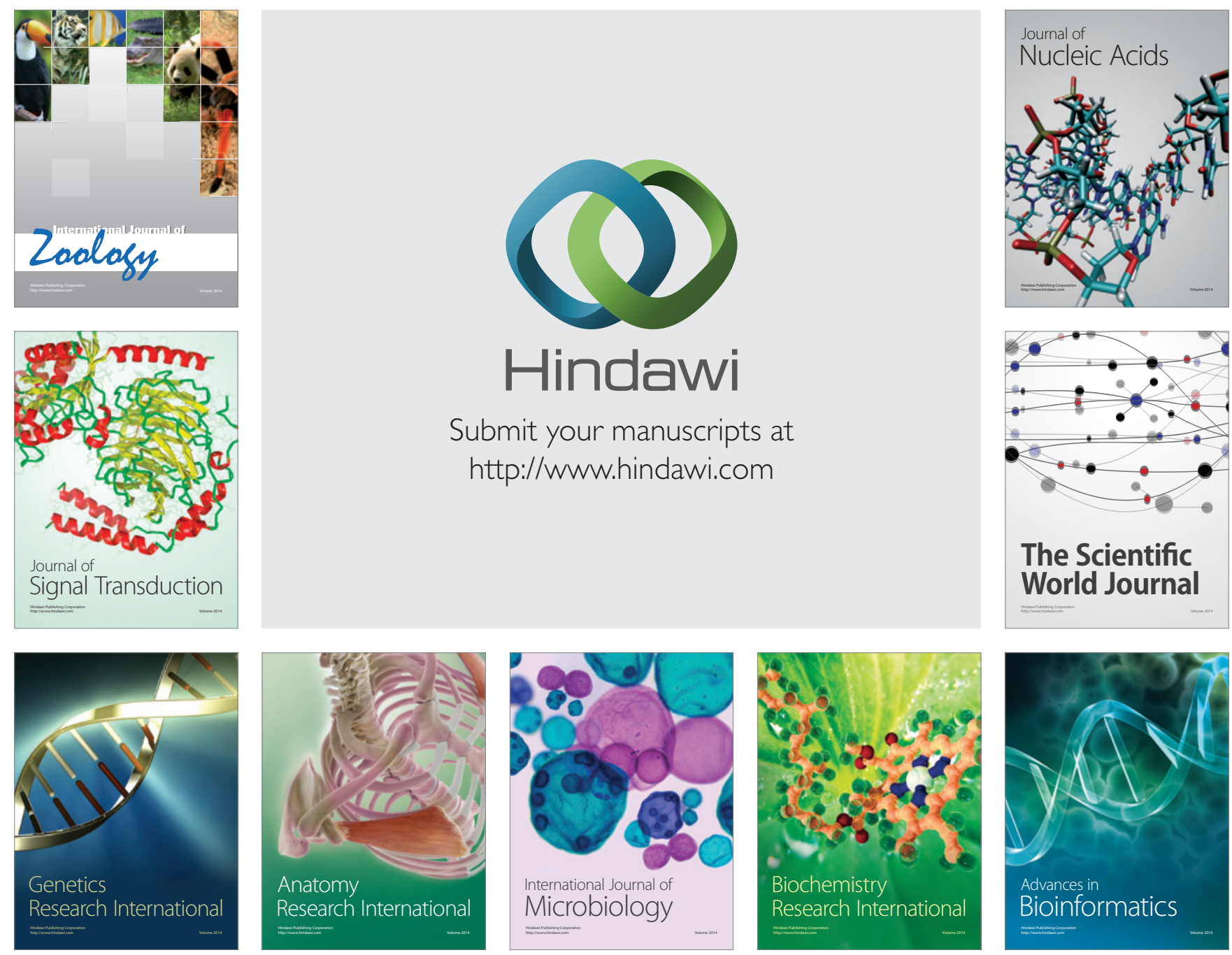

The Scientific World Journal
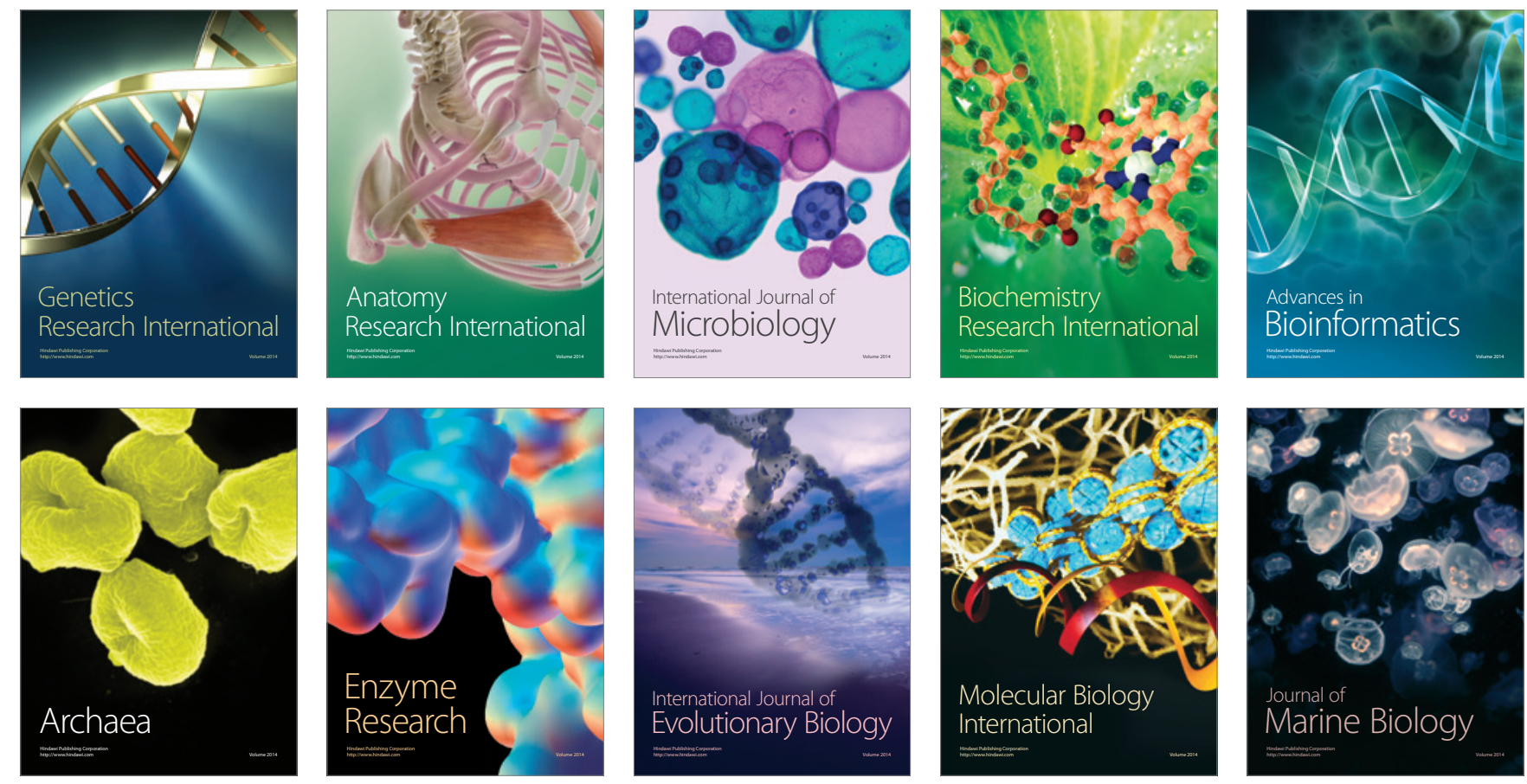